\title{
AUMC Over Dosing Interval Normalized by
} Surface Area

National Cancer Institute

\section{Source}

National Cancer Institute. AUMC Over Dosing Interval Normalized by Surface Area. NCI

Thesaurus. Code C92340.

The area under the first moment curve (AUMC) for the defined interval between doses (TAU) divided by the surface area. 